Sex, grade-level and stream differences in learning environment and attitudes to science in Singapore primary schools

Jarina Peer and Barry J. Fraser

Contact Author: Barry Fraser

Jarina Peer - Barry Fraser ( $\square$ )

Jarina Peer

Ministry of Education, Singapore

Barry Fraser

Science and Mathematics Education Centre

Curtin University

GPO Box U1987

Perth WA 6845

Australia

Tel: 61892667896

Fax: 61892662503

Email: B.Fraser@curtin.edu.au 


\title{
Sex, grade-level and stream differences in learning environment and attitudes to science in Singapore primary schools
}

\begin{abstract}
Learning environment research provides a well-established approach for describing and understanding what goes on in classrooms and has attracted considerable interest in Singapore. This article reports the first study of science classroom environments in Singapore primary schools. Ten scales from the What Is Happening In this Class? (WIHIC), Constructivist Learning Environment Survey (CLES) and Test Of Science Related Attitudes (TOSRA) were administered to 1081 students in 55 classes. Factor and reliability analyses provided strong support for this widely-applicable questionnaire for assessing Involvement, Teacher Support, Investigation, Task Orientation, Cooperation, Personal Relevance, Uncertainty, Student Negotiation, Attitude to Inquiry and Enjoyment of Science Lessons among Singaporean primary-school students. Statistically significant findings of small magnitude emerged for sex differences, grade-level differences, stream differences, the stream-by-sex interaction and the grade-by-stream interaction.
\end{abstract}

Keywords Attitudes; Constructivist Learning Environment Survey (CLES); Grade-level differences; Learning environment; Science classrooms; Sex differences; Singapore; Stream differences; Test of Science Related Attitudes (TOSRA); What Is Happening In this Class? (WIHIC)

\section{Introduction and background}

The learning environment refers to the social, psychological and pedagogical contexts in which learning occurs and which affect student achievement and attitudes. In the 40 years since the pioneering use of classroom environment assessments by Herbert Walberg and Rudolf Moos (Moos and Trickett 1974; Walberg and Anderson 1968), the field of learning environments has undergone remarkable growth, diversification and internationalisation. Few fields of educational research have 
such a rich diversity of valid, economical and widely-applicable assessment instruments as does the field of learning environments (Fraser 2012). The widespread international research on learning environments includes considerable interest in Singapore (Goh and Fraser 1998; Chionh and Fraser 2009; Fraser 2012). A positive classroom climate is needed for effective learning (Emmer, Evertson and Anderson 1980), thus highlighting the importance of the study of learning environments.

This section places the present study of science learning environments in Singapore into context by providing: a historical perspective on the field of learning environments; and a review of previous learning environment studies in Singapore.

Historical perspective on learning environment research

Existing research on learning environments owes its inspiration to some extent to Lewin's (1936) formative work in non-educational settings, which recognised that both the environment and its interaction with characteristics of the individual are strong determinants of human behaviour. Studies of the environment of educational settings and its effects on student outcomes began in the 1960s when Walberg and Moos began the early development of assessment tools, which later became the foundation of the field of learning environments as we know it today. An evaluation of Harvard Project Physics led to the development of the Learning Environment Inventory (LEI) (Walberg and Anderson 1968). Moos (1974) developed a series of human environment measures which ultimately led to the Classroom Environment Scale (CES, Moos and Trickett 1974). These two instruments provided the momentum for a variety of research applications and a basis for the development of other instruments (Fraser 2007, 2012).

Reviewing the voluminous program of learning environment research which grew out of the work of Walberg and Moos is beyond the scope of this article. Much of this work can be found in books (Fisher and Khine 2006; Fraser 1986; Khine and Fisher 2003), literature reviews (Fraser 2004, 2007, 2012, in press) and Springer's Learning Environments Research: An International Journal. For the purposes of this article, only a brief review of some of this work is provided below. 
Few fields of educational research are blessed with the rich diversity of valid, economical and widely-applicable assessment instruments as the field of learning environments. Fraser's (1998) review encompasses most of the frequently-used learning environment questionnaires, such as the Questionnaire on Teacher Interaction (QTI), My Class Inventory (MCI), Science Laboratory Environment Inventory (SLEI), Constructivist Learning Environment Survey (CLES) and What Is Happening In this Class? (WIHIC). According to Dorman (2008, p. 181), "the WIHIC has achieved almost bandwagon status in the assessment of classroom environments". Additionally, the WIHIC has formed the basis for the development of more recent learning environment questionnaires, such as the Technology-Rich Outcomes-Focused Learning Environment Inventory (TROFLEI, Aldridge and Fraser 2008) and the Constructivist-Oriented Learning Environment Survey (COLES, Aldridge, Fraser, Bell and Dorman 2012). Several of these instruments are considered further below in the section devoted to past learning environment research in Singapore.

Reviews of research (Fraser 2012, in press) reveal that some of the main foci in past studies involving classroom environment instruments include (1) evaluation of educational innovations (Lightburn and Fraser 2007; Martin-Dunlop and Fraser 2008), (2) associations between the classroom environment and student outcomes (McRobbie and Fraser 1993; Wong, Young and Fraser 1997), (3) teachers' action research attempts to improve their learning environments (Aldridge, Fraser, Bell and Dorman 2012), (4) the joint influence of the environments of the school, home and peer group (Fraser and Kahle 2007), (5) typologies of classroom learning environments (den Brok, Telli, Cakiroglu, Taconis and Takkaya 2010), (6) person-environment fit studies of whether students achieve better in their preferred classroom environment (Fraser and Fisher 1983) and (7) their use as accountability tools for school counsellors (Sink and Spencer 2005). The review of past research in Singapore in the next section includes some of the above lines of research.

Learning environments research has not only expanded remarkably on the international scene generally, but Asian researchers specifically have also made important and distinct contributions. Asian researchers have cross-validated the main contemporary learning environment questionnaires that originated in the West and have undertaken careful translations and adaptations for use in the Chinese, Korean, Malay, Indonesian, and Arabic languages (Fraser 2012; MacLeod and Fraser 2010). 
Asian studies have successfully replicated Western research in establishing consistent associations between the learning environment and student outcomes, in using learning environment assessments in evaluation of educational programmes and in identifying determinants of learning environments (Fraser 2002).

Learning environments research in Singapore

Table 1 provides an overview on the main published studies of learning environments conducted in Singapore. In the first learning environment study in Singapore, Teh and Fraser (1994) used learning environment criteria as a source of dependent variables in evaluating computer-assisted learning in geography. Using a sample of 671 Singaporean high school students in 24 classes and an instrument designed by the researchers, a comparison was made between a control group and an experimental group using micro-PROLOG-based computer-assisted learning. The experimental group had much larger scores for achievement (3.5 standard deviations), attitudes (1.4 standard deviations) and classroom environment (1.0-1.9 standard deviations) relative to the control group. As well, Teh and Fraser (1995) reported associations between classroom environment and the student outcomes of achievement and attitudes.

Wong and Fraser (1996) modified the Science Laboratory Environment Inventory (SLEI) to form the Chemistry Learning Environment Inventory (CLEI) and validated it with a sample of 1592 Singaporean Grade 10 students in chemistry classes. Statistically significant associations were found between the classroom environment and numerous science-related attitudes (Wong, Young and Fraser, 1997). In another Singaporean study, Quek, Wong and Fraser (2005) used the CLEI together with measures of teacher-student interactions and student attitudes towards chemistry among 497 gifted and non-gifted secondary-school chemistry students. Stream (gifted versus non-gifted) and sex differences were found in actual and preferred chemistry laboratory classroom environments and teacher-student interactions.

A major study undertaken at the primary-school level in Singapore involved mathematics classrooms in 13 government co-educational elementary schools (Goh and Fraser 1998, 2000; Goh, 
Young and Fraser 1995). This study with 1512 Singaporean students in 39 mathematics classes explored two aspects of the learning environment, interpersonal teacher behaviour and classroom climate, using the Questionnaire on Teacher Interaction (QTI) and My Class Inventory (MCI), respectively. Student-teacher relationships and classroom climate were significantly related to students' achievement and attitudes. This study also showed that teacher cooperation (involving being understanding, helpful and friendly) involves positive behaviours that teachers should demonstrate in primary classrooms. It also showed that classroom environment was conducive to learning when there was a high degree of cohesion and little friction among students.

Pang (1999) used a case study to explore the impact of a cooperative learning environment on underachievers in a Primary 4 classroom. Underachieving students responded positively, with more active participation in class activities, increased confidence and self-esteem, and better relationships with peers. Another study, involving seven classes of Primary 5 science classrooms in a coeducational government primary school (Chin 2001), examined relationships between students' perceptions of their science classroom environment and their achievement and attitudes towards learning of science. A more positive learning environment was linked with better students' academic performance and attitudes towards learning.

Khoo and Fraser (2008) used a learning environment instrument to evaluate the effectiveness of computing courses attended by 250 adults in five computer education centres in Singapore. Factor analysis supported a five-factor learning environment questionnaire. In this study, students perceived their learning environments favourably in terms of the levels of trainer support, task orientation and equity. Student satisfaction varied between the sexes and between students of different ages.

Chionh and Fraser (2009) used the What Is Happening In this Classroom? (WIHIC) questionnaire among 2310 Singaporean Grade 10 students in 75 geography and mathematics classes in 38 schools. A seven-scale factor structure was strongly supported and the alpha reliability of each scale was high. An investigation of associations between classroom environment and several student outcomes revealed that better examination scores were found in classrooms with more student cohesiveness, whereas self-esteem and attitudes were more favourable in classrooms with more teacher support, task orientation and equity. 
Chua, Wong and Chen (2011) used the Chinese Language Classroom Environment Inventory (CLCEI) to investigate the nature of Chinese language classroom environments in Singapore secondary schools. The investigation was carried out using a sample of 1460 secondary three students from 50 Chinese language classes. Although both the Chinese Language teachers and students perceived their present classroom learning environments positively, they would have liked improvements in all the six dimensions of the classroom learning environments under investigation. Also teachers perceived a more positive classroom learning environment than their students in the same class. In addition, female students perceived their actual and preferred classroom environments more positively than did their male counterparts.

\section{Purposes}

To date, there has been no study of science learning environments in Singaporean primary schools. This is the gap in the study of learning environments that our research filled. The two purposes of our study were to (1) validate an instrument suitable for assessing the classroom learning environment and student attitudes in primary science classes in Singapore and (2) investigate sex, grade-level and stream differences in learning environment perceptions and attitudes to science.

\section{Methods}

The instrument used to assess students' perceptions of their classroom learning environment in our study included scales based on the Constructivist Learning Environment Survey (CLES) (Aldridge et al. 2000; Taylor, Fraser and Fisher 1997) and the What Is Happening In this Class? (WIHIC) (Aldridge, Fraser and Huang 1999; Fraser, Fisher and McRobbie 1996) questionnaires. To assess students' attitudes towards science, two attitude scales were based on the Test Of Science-Related Attitudes (TOSRA) (Fraser 1978, 1981). The scales chosen were Personal Relevance, Uncertainty and Student Negotiation from the CLES, Teacher Support, Involvement, Investigation, Cooperation and 
Task Orientation from the WIHIC, and Enjoyment of Science Lessons and Attitude to Scientific Inquiry from the TOSRA.

Data were gathered from 1081 students from 55 different classes in 4 schools in Singapore. These students were from Gifted Education (GE) classes and High Ability (HA) classes. Of these students, there were 394 (36.4\%) Grade 4 students, 401 (37.1\%) Grade 5 students and 286 (26.5\%) Grade 6 students. There were 665 (61.5\%) male students and 416 (38.5\%) female students.

Validation of the questionnaire for use with the students in this study involved principal axis factoring followed by varimax rotation and Kaiser normalisation. Only items with a factor loading of 0.40 or above on their own scale and less than 0.40 on all other scales were retained. To check whether every item in each learning environment and attitude scale assessed a similar construct, the internal consistency reliability was calculated. The Cronbach alpha coefficient was calculated using two units of analysis (individual and class mean) as the index of scale of internal consistency. Oneway ANOVA was used to determine the ability of each learning environment scale to differentiate significantly between the perceptions of the students from the different classrooms. The eta ${ }^{2}$ statistic, which is a measure of the degree of association between class membership and the dependent variable for each of the learning environment scales, was calculated.

\section{Results: Validity of questionnaire}

When factor analysis was conducted for the 70 items in the eight learning environment and two attitude scales based on the CLES, WIHIC and TOSRA, 61 items were retained in the same 10-factor structure: Involvement, Teacher Support, Investigation, Task Orientation, Cooperation, Personal Relevance, Uncertainty, Student Negotiation, Scientific Inquiry and Enjoyment. The criteria used to retain an item were that it must have a factor loading of 0.40 or above with its a priori scale and below 0.40 with each of the other scales. The factor analysis confirmed the a priori structure of the instrument comprising 8 learning environment and two attitude scales. Therefore the 61 -item version of the questionnaire, containing learning environment scales based on the WIHIC (5 scales with 4-8 items in each) and the CLES ( 3 scales with 4-5 items in each) and two 6-item attitude scales based on 
the TOSRA, was accepted. Table 2 shows the factor analysis results for learning environment and attitude questionnaire.

Table 2 here

The percentage of variance for different scales ranged from $1.95 \%$ to $27.92 \%$, summing to a total of $58.9 \%$ variance for all 10 scales combined (see Table 2). The eigenvalues for the 10 different scales ranged from 1.36 to 19.54 . The factor analysis results strongly supported the factor structure of the 61-item questionnaire and attested to the independence of factor scores on the 10 learning environment and attitude scales.

To check whether every item in each of the 10 scales assesses a similar construct, the internal consistency reliability was calculated using the Cronbach alpha coefficient. Table 3 shows the Cronbach alpha coefficient for each of the 10 scales (namely, five scales based on the WIHIC, three scales based on the CLES, and two attitude scales based on the TOSRA) using two units of analysis (individual and class mean). When using the individual student scores as the unit of analysis, the alpha coefficient for the 10 different scales ranged from 0.77 to 0.94 . When using the class mean as the unit of analysis, the alpha coefficient for the 10 different scales were higher and ranged from 0.77 to 0.98 (see Table 3). The highest alpha reliability was obtained for the Enjoyment scale and the lowest for the scale Uncertainty.

Table 3 here

One-way ANOVA was used to determine the ability of each learning environment scale to differentiate significantly between the perceptions of science students from the different classrooms. (This was not relevant for the attitude scales.) For each ANOVA, scores on one of the learning environment scales constituted the dependent variable and class membership was the independent variable. ANOVA results for each of the eight learning environment scales are reported in Table 3 for the sample of 1081 students in 55 classes. The eta ${ }^{2}$ statistic, which is a measure of the degree of 
association between class membership and a learning environment scale, ranged from 0.06 to 0.13 for different scales and was statistically significant $(p<0.05)$ for each scale (see Table 3 ). Overall, the ANOVA results provide further evidence that the learning environment scales based on the WIHIC and CLES were valid when used with my sample in Singapore.

Overall, the results reported in this section suggest that the learning environment scales based on the CLES and WIHIC and the attitude scales based on the TOSRA were valid and reliable when used with our sample of elementary school students in Singapore. Our findings in Singapore replicate other validity studies involving the WIHIC in Florida (Allen and Fraser 2007), Singapore (Chionh and Fraser 2009; Khoo and Fraser 2008), Australia (Dorman 2008), the United States (Wolf and Fraser 2008), India (Koul and Fisher 2005), Australia, Canada and United Kingdom (Dorman 2003), Australia and Canada (Zandvliet and Fraser 2004, 2005) and Australia and Indonesia (Fraser, Aldridge and Adolphe 2010); the CLES in California (Ogbuehi and Fraser 2007), Korea (Kim, Fisher and Fraser 1999), Australia and Taiwan (Aldridge et al. 2000), South Africa (Aldridge, Fraser and Sebela 2004) and the United States (Dryden and Fraser 1996; Johnson and McClure 2004; Nix et al. 2005; Peiro and Fraser 2009); and studies using the original, modified and/or translated versions of the TOSRA in Australia (McRobbie and Fraser 1993), Brunei (Scott and Fisher 2004), Singapore (Wong and Fraser 1996; Wong et al. 1997), Taiwan and Australia (Aldridge, Fraser and Huang 1999), Indonesia and Australia (Fraser, Aldridge and Adolphe 2010) and the USA (Martin-Dunlop and Fraser 2008).

Item means and standard deviations were computed to portray the nature of the science learning environment. The relatively high mean scores for all scales (see Table 3) suggest a positive classroom environment, with the mean scores ranging between 3.05 and 4.05. (A score of 3 corresponds to the Sometimes response for each item and a score of 4 corresponds to the Often response.) The standard deviation for all the scales was less than 1.08, suggesting that there was limited diversity in students' perceptions. Generally, students perceived a positive science classroom learning environment.

\section{Sex, grade-level and stream differences in learning environment and attitudes to science}


Once the validity of the refined instrument was established, the same data were then used to investigate sex (male, female), grade-level (Grades 4, 5 and 6) and stream (Gifted Education, GE and High Ability, HA) differences in the learning environment and attitudes to science. A three-way multivariate analysis of variance (MANOVA) was conducted with the learning environment and attitude scales as the dependent variables and with sex, grade-level and stream as the three independent variables. Because the MANOVA produced statistically significant results using Wilks' lambda criterion, the three-way univariate ANOVA (sex, grade level and stream) was interpreted separately for each dependent variable. The MANOVA and ANOVAs also identified the presence of any stream-by-sex, grade-by-stream, grade-by-sex and stream-by-sex-by-grade interactions for each scale.

Table 4 provides the three-way ANOVA results for each of the 10 learning environment and attitude scales. This table shows the $F$ values and the eta ${ }^{2}$ values of the scales for sex, grade-level and stream differences and their interactions. Eta ${ }^{2}$ indicates the effect size in terms of the proportion of variance in a dependent variable explained by an independent variable. An overview of this table reveals the following statistically significant findings (which are discussed in detail below):

- significant sex differences for Involvement, Teacher Support, Task Orientation and Cooperation

- significant grade-level differences for Teacher Support, Task Orientation, Cooperation and Enjoyment

- $\quad$ significant stream differences for Involvement, Cooperation and Personal Relevance

- $\quad$ significant stream-by-sex interactions for Task Orientation and Enjoyment

- significant grade-by-stream interactions for Investigation, Student Negotiation, Scientific Inquiry and Enjoyment

- no significant grade-by-sex or stream-by-sex-by-grade interaction for any dependent variable. 
Table 4 here

Sex differences in learning environment and attitudes to science

For the sample of 1081 students in 55 classes, there were $665(61.5 \%)$ male students and $416(38.5 \%)$ female students. Table 5 reports the average item mean, average item standard deviation and difference between male and female students in scores on each environment and attitude scale. To allow simple comparison of the average scores on the different scales, the average item mean (scale mean divided by the number of items in that scale) and average item standard deviation for each learning environment and attitude scale are reported in Table 5 for male and female students. The $F$ ratios in Table 5 show the statistical significance of sex differences for each scale and they are taken from the three-way ANOVA results in Table 4. Table 5 shows that sex differences were statistically significant $(p<0.05)$ for the four learning environment scales of Involvement, Teacher Support, Task Orientation and Cooperation.

The effect size, which is the difference between the means of the two sex groups divided by the pooled standard deviation, was also calculated for each learning environment and attitude scale (see Table 5). The effect sizes displayed in Table 5 are consistent with the ANOVA results in that the magnitudes of the differences between males and females for the four scales for which gender differences were statistically significant (namely, Involvement, Teacher Support, Task Orientation and Cooperation) were relatively small (ranging from 0.14 to 0.29 standard deviations). These magnitudes suggest that the differences between the males and females are of minor educational significance.

Table 5 shows that males had higher means than females for the majority of scales. However, for the four scales that showed a statistically significant difference, females scored more highly than males on three of the scales. Male students perceived higher levels of Involvement in their classroom environment than their female counterparts, but that females perceived higher levels of Teacher Support, Task Orientation and Cooperation than their male counterparts. Because the presence of 
interactions can confound the interpretation of main effects, and because there were some statistically significant interactions involving sex (Table 4), our discussion of sex differences is revisited below.

Grade-level differences in learning environment and attitudes to science

For the sample of 1081 students from 55 classes, there were 394 (36.4\%) Grade 4 students, 401 (37.1\%) Grade 5 students and 286 (26.5\%) Grade 6 students. The ANOVA results reported in Table 4 show that grade-level differences were statistically significant $(p<0.05)$ for three of the eight learning environment scales (namely, Teacher Support, Task Orientation and Cooperation) and one attitude scale (Enjoyment). The $F$ values from Table 4 are reported in Table 6, along with the average item mean and average item standard deviation for each learning environment and attitude scale for each of the three grade levels. An inspection of means for the scales for which grade-level differences were statistically significant revealed that Grade 6 students had the highest mean for the three learning environment scales and Grade 4 students had the highest mean for the attitude scale. The eta ${ }^{2}$ values for the three scales for which grade-level differences were statistically significant was only 0.01 , suggesting that relatively little variance in scores on these scales was attributable to grade level.

Table 6 here

A pattern that is evident in Table 6 is that Grade 6 students had higher scores for Teacher Support and Cooperation than students in either Grade 4 or 5. The lowest score for Teacher Support was for Grade 5 students whereas, for Cooperation, Grade 4 and 5 students had similar scores. For Task Orientation, Grade 6 students had the highest score and Grade 5 students had the lowest score. For Enjoyment, Grade 4 students had the highest score and Grade 5 and 6 students had lower but similar scores. Again, because the presence of interactions confounds the interpretation of main effects, and because there were some statistically significant interactions involving grade level (Table 4), our discussion of grade-level results in this Section is revisited below in Section 4.3.4. 
Stream differences in learning environment and attitudes to science

For the sample of 1081 students in 55 classes, there were 569 (52.6\%) students in the GE (Gifted Education) stream and $512(47.4 \%)$ students in the HA (High Ability) stream. $F$ ratios from three-way ANOVAs (reported previously in Table 4 and reproduced in Table 7) show that stream differences were statistically significant $(p<0.05)$ for three out of the eight learning environment scales (namely, Involvement, Cooperation and Personal Relevance). For the attitude scales, there was no statistically significant difference between streams.

Table 7 here

The effect size, or the difference between the means of the two groups divided by the pooled standard deviation, for each learning environment and attitude scale is also reported in Table 7. These effect sizes confirm the ANOVA results in that the magnitudes of the differences between the two streams (GE and HA) for the three environment scales for which differences were statistically significant (namely, Involvement, Cooperation and Personal Relevance) were small and ranged from only 0.15 to 0.17 standard deviations, suggesting a small degree of educational importance for the differences between streams.

Table 7 shows that GE students perceived higher levels of Involvement in their classroom environments than their HA counterparts, but HA pupils perceived higher levels of Cooperation and Personal Relevance than their GE counterparts. A pattern that is evident is that the HA students had higher scores than their GE counterparts for most scales. Although the magnitudes for between-stream differences are small, Table 7 shows a consistent pattern in terms of the direction of the differences. It is interesting to note that, of the 10 scales, HA students scored a higher mean than the GE students for 8 scales. Statistically significant stream differences were found between gifted and the high-ability students, with the HA students having higher scores for Cooperation and Personal Relevance. Because 
the presence of interactions confounds the interpretation of main effects, and because there were some statistically significant interactions involving stream (Table 4), our discussion of stream results is revisited below.

Stream-by-sex interactions for learning environment and attitudes to science

The results of the three-way ANOVAs in Table 4 show that the scales for which the stream-by-sex interaction was statistically significant were Task Orientation and Enjoyment. Furthermore, because a significant main effect for sex and stream also occurred for Task Orientation (see Tables 4 and 5), it is important to revisit the interpretation of main effects. The interpretation of both the significant sex effect and the significant sex-by-stream interaction for Task Orientation and Enjoyment is illustrated graphically in Figure 1. This figure shows the mean Task Orientation scores obtained by four groups, namely, GE males, GE females, HA males and HA females. For male students, Task Orientation scores were higher for HA students than GE students but, for female students, Task Orientation scores were higher for GE students than HA students. For male students, Enjoyment scores were higher for HA students than GE students but, for female students, Enjoyment scores for GE students were slightly higher than the HA students.

Figure 1 here

Figure 1 clearly shows that our earlier interpretation of the sex effect (i.e. the females having higher Task Orientation scores than the males) is too simple and needs to be moderated in the presence of the sex-by-stream interaction. Figure 1 shows that the interpretation of this interaction is that females had higher Task Orientation scores than males only in the GE stream, but that sex differences were negligible in the HA stream.

The presence of a significant sex-by-stream interaction suggests that our previous interpretation of there being no sex differences and no stream differences overall in Enjoyment is 
oversimplified. Figure 1 shows that, although there was a negligible sex difference in Enjoyment in the GE stream, enjoyment in the HA stream was higher for males than females.

Grade-by-stream interactions for learning environment and attitudes to science

The three-way MANOVA/ANOVAs identified that the interaction between grade-level and stream (see Table 4) was statistically significant for Investigation, Student Negotiation, Attitude to Scientific Inquiry and Enjoyment. In order to interpret these four grade-by-stream interactions, the graphs in Figure 2 were constructed to depict the six means for the different combinations of grade level (Grades 4, 5 and 6) and stream (GE and HA).

Figure 2 here

For Grade 4 students, HA scores were lower than GE scores for Investigation, Student Negotiation and Scientific Inquiry. However, for Enjoyment, HA and GE scores were comparable. For Grade 5 students, HA scores were higher than GE scores for all four scales. For Grade 6 students, HA scores were lower than GE scores for the three scales of Student Negotiation, Scientific Inquiry and Enjoyment. However, HA scores were higher than GE scores for Investigation (as shown in Figure 2).

Figure 2 clearly shows that our earlier interpretation of the grade-level effect (i.e. the Grade 4 students scored highest for Enjoyment and Grade 6 students scored lowest for Enjoyment) is too simple and needs to be moderated because of the presence of the grade-by-stream interaction. The interpretation of this interaction is that the Grade 4 students had the highest mean for all three grade levels. However, HA students in Grade 5 had higher scores for Enjoyment than HA students in Grade 6, whereas GE students in Grade 5 had lower scores than HA students in Grade 6. The eta ${ }^{2}$ values (reported in Table 4) were only 0.01 for these interactions, suggesting that relatively little variance in the scores on these scales was attributable to stream-by-sex interactions. 


\section{Significance and conclusion}

This study is significant in that it involved validating and making available a widely-applicable learning environment questionnaire for researchers and teachers. Also it was the first time that any learning environment research focused on primary science classrooms in Singapore. As well, our study is the first in Singapore to investigate simultaneously sex, grade-level and stream differences in the learning environment and student attitudes.

For a sample of 1081 primary science students in 51 classes, factor and reliability analyses provided strong support for a questionnaire assessing involvement, teacher support, investigation, task orientation, cooperation, personal relevance, uncertainty, student negotiation, attitude to inquiry and enjoyment of science lessons. As well, statistically significant findings of small magnitude emerged for sex differences, grade-level differences, stream differences, the stream-by-sex interaction and the grade-by-stream interaction.

The study furnished teachers and policy makers in Singapore with data regarding the present learning environment in primary GE and HA classes, as well as grade-level and sex differences. These data have the potential to assist teachers in identifying factors that contribute towards creating a positive learning environment that fosters positive attitudes towards science. Thus our research is significant for teachers of high-ability children as it provides potentially-useful information to teachers, researchers and teacher educators.

This study suggests avenues for future research involving learning environment and attitudes of students. Because the questionnaire that was validated in this study is versatile and economical, it could be used in future research in Singapore to measure the learning environment of other disciplines besides science. It might be illuminating to compare actual and ideal perceptions of the classroom learning environment. Future research could compare single-sex (either all males or all females) schools with mixed-sex schools in terms of students' perceptions of classroom learning environment. Further evaluation studies could be conducted in Singapore to monitor changes in the learning environment when new educational programmes are implemented in classrooms (Khoo and Fraser 
2008). Finally the learning environment questionnaire validated in our study could be used in teacher action research aimed at improving classroom learning environments (Aldridge et al. 2012). 


\section{References}

Allen, D., \& Fraser, B.J. (2007). Parent and student perceptions of classroom learning environment and its association with student outcomes. Learning Environments Research, 10, 67-82.

Aldridge, J.M., \& Fraser, B.J. (2008). Outcomes-focused learning environments:

Determinants and effects. (Advances in Learning Environments Research series). Rotterdam, The Netherlands: Sense Publishers.

Aldridge, J.M., Fraser, B.J., Bell, L., \& Dorman, J.P. (2012). Using a new learning environment questionnaire for reflection in teacher action research. Journal of Science Teacher Education, 23, 259-290.

Aldridge, J.M., \& Fraser, B.J., \& Huang, I.T.-C. (1999). Investigating classroom environments in Taiwan and Australia with multiple research methods. Journal of Educational Research, 93, $48-62$.

Aldridge, J.M., Fraser, B.J., \& Sebela, M.P. (2004). Using teacher action research to promote constructivist learning environments in South Africa. South African Journal of Education, 24, 245-253.

Aldridge, J. M., Fraser, B. J., Taylor, P. C., \& Chen, C. C. (2000). Constructivist learning environments in a cross-national study in Taiwan and Australia. International Journal of Science Education, 22, 37-55.

Chin, T. Y. (2001). Pupils' classroom environment perceptions, attitudes and achievement in science at the upper primary level. Unpublished MEd dissertation, National Institute of Education, Nanyang Technological University, Singapore.

Chionh, Y. H., \& Fraser, B. J. (2009). Classroom environment, achievement, attitudes and selfesteem in geography and mathematics in Singapore. International Research in Geographical and Environmental Education, 18(1), 29-44. 
Chua, S. L., Wong, A. F. L., \& Chen, V. D. (2011). The nature of Chinese Language classroom learning environments in Singapore secondary schools. Learning Environments Research, 14, $75-90$.

den Brok, P., Telli, S., Cakiroglu, J., Taconis, R., \& Tekkaya, C. (2010). Learning environment profiles of Turkish secondary biology students. Learning Environments Research, 13, 187204.

Dorman, J.P. (2003). Cross-national validation of the What Is Happening In this Class? (WIHIC) questionnaire using confirmatory factor analysis. Learning Environments Research, 6, 231245.

Dorman, J.P. (2008). Use of multitrait-multimethod modelling to validate actual and preferred forms of the What Is Happening In this Class? (WIHIC) questionnaire. Learning Environments Research, 11, 179-197.

Dryden, M., \& Fraser, B.J. (1996, April). The impact of systemic reform efforts in promoting constructivist approaches in high school science. Paper presented at the annual meeting of the American Educational Research Association, San Diego, CA.

Emmer, E., Evertson, C., \& Anderson, L. (1980). Effective classroom management at the beginning of the school year. Elementary School Journal, 80, 219-231.

Fisher, D.L. \& Khine, M.S. (Eds) (2006). Contemporary approaches to research on learning environments: Worldviews. Singapore: World Scientific.

Fraser, B. J. (1978). Development of a test of science-related attitudes. Science Education, 62, 509515.

Fraser, B. J. (1981). Test of Science Related Attitudes. Melbourne: Australian Council for Educational Research.

Fraser, B.J. (1986). Classroom environment. London: Croom Helm.

Fraser, B. J. (1994). Research on classroom and school climate. In D. Gabel (Ed.), Handbook of research on science teaching and learning (pp. 493-540). New York: Macmillan. 
Fraser, B. J. (1998). Classroom environment instruments: Development, validity and applications. Learning Environments Research, 1, 7-34.

Fraser, B.J. (2002). Learning environments research: Yesterday, today and tomorrow. In S.C. Goh \& M.S. Khine (Eds.), Studies in educational environments: An international perspective (pp. 125). Singapore: World Scientific.

Fraser, B. J. (2007). Classroom learning environments. In S. K. Abell \& N. G. Lederman (Eds.), Handbook of research on science education (pp. 103-124). Mahwah, NJ: Lawrence Erlbaum.

Fraser, B. J. (2012). Classroom learning environments: Retrospect, context and prospect. In B. J. Fraser, K. G. Tobin, \& C. J. McRobbie (Eds.), Second international handbook of science education (pp. 1191-1239). New York: Springer.

Fraser, B.J. (in press). Classroom climate. In J.D. Wright (Ed.), International encyclopedia of social and behavioral sciences ( $2^{\text {nd }}$ ed.). London: Elsevier.

Fraser, B.J. Aldridge, J.M., \& Adolphe, F.S.G. (2010). A cross-national study of secondary science classroom environments in Australia and Indonesia. Research in Science Education, 40, 551 571.

Fraser, B.J., \& Fisher, D.L. (1983c). Use of actual and preferred classroom environment scales in person-environment fit research. Journal of Educational Psychology, 75, 303-313.

Fraser, B. J., Fisher, D. L., \& McRobbie, C. J. (1996, April). Development, validation and use of personal and class forms of a new classroom environment instrument. Paper presented at the annual meeting of the American Educational Research Association, New York.

Fraser, B.J., \& Kahle, J.B. (2007). Classroom, home and peer environment influences on student outcomes in science and mathematics: An analysis of systemic reform data. International Journal of Science Education, 29, 1891-1909.

Goh, S. C., \& Fraser, B. J. (1998). Teacher interpersonal behaviour, classroom environment and student outcomes in primary mathematics in Singapore. Learning Environments Research, 1, $199-229$. 
Goh, S. C., \& Fraser, B. J. (2000). Teacher interpersonal behavior and elementary students' outcomes. Journal of Research in Childhood Education, 14, 216-231.

Goh, S.C., Young, D.J., \& Fraser, B.J. (1995). Psychosocial climate and student outcomes in elementary mathematics classrooms: A multilevel analysis. Journal of Experimental Education, 64, 29-40.

Johnson, B., \& McClure, R. (2004). Validity and reliability of a shortened, revised version of the Constructivist Learning Environment Survey (CLES). Learning Environments Research, 7, 65-80.

Khine, M.S., \& Fisher, D.L. (Eds.). (2003). Technological learning environments: A future perspective. Singapore: World Scientific.

Khoo, H. S., \& Fraser, B. J. (2008). Using classroom psychosocial environment in the evaluation of adult computer application courses in Singapore. Technology, Pedagogy and Education, 17, $67-81$.

Kim, H.B., Fisher, D.L., \& Fraser, B.J. (1999). Assessment and investigation of constructivist science learning environments in Korea. Research in Science and Technological Education, 17, 239249.

Koul, R.B., \& Fisher, D.L. (2005). Cultural background and students' perceptions of science classroom learning environment and teacher interpersonal behaviour in Jammu, India. Learning Environments Research, 8, 195-211.

Lewin, K. (1936). Principles of topological psychology. New York: McGraw.

Lightburn, M.E., \& Fraser, B.J. (2007). Classroom environment and student outcomes among students using anthropometry activities in high school science. Research in Science and Technological Education, 25, 153-166.

MacLeod, C., \& Fraser, B.J. (2010). Development, validation and application of a modified Arabic translation of the What Is Happening In this Class? (WIHIC) questionnaire. Learning Environments Research, 13, 105-125. 
Martin-Dunlop, C., \& Fraser, B.J. (2008). Learning environment and attitudes associated with an innovative course designed for prospective elementary teachers. International Journal of Science and Mathematics Education, 6, 163-190.

McRobbie, C.J., \& Fraser, B.J. (1993). Associations between student outcomes and psychosocial science environment. Journal of Educational Research, 87, 78-85.

Moos, R.H. (1974). The social climate scales: An overview. Palo Alto, CA: Consulting Psychologists Press.

Moos, R. H., \& Trickett, E. J. (1974). Classroom Environment Scale manual. Palo Alto, CA: Consulting Psychologists Press.

Nix, R.K., Fraser, B.J., \& Ledbetter, C.E. (2005). Evaluating an integrated science learning environment using the Constructivist Learning Environment Survey. Learning Environments Research, 8, 109-133.

Ogbuehi, P.I., \& Fraser B.J. (2007). Learning environment, attitudes and conceptual development associated with innovative strategies in middle-school mathematics. Learning Environments Research, 10, 101-114.

Pang, S. S. (1999). Case study of underachievers in a co-operative learning classroom. Unpublished MEd dissertation, National Institute of Education, Nanyang Technological University, Singapore.

Peiro, M.M., \& Fraser, B.J. (2009). Assessment and investigation of science learning environments in the early childhood grades. In M. Ortiz and C. Rubio (Eds.), Educational evaluation: $21^{\text {st }}$ century issues and challenges (pp. 349-365). New York: Nova Science Publishers.

Quek, C. L., Wong, A. F. L., \& Fraser, B. J. (2005). Student perceptions of chemistry laboratory learning environments, student-teacher interactions and attitudes in secondary school gifted education classes in Singapore. Research in Science Education, 35, 299-321.

Scott. R.H., \& Fisher, D.L. (2004). Development, validation and application of a Malay translation of an elementary version of the Questionnaire on Teacher Interaction (QTI). Research in Science Education, 34, 173-194. 
Sink, C.A., \& Spencer, L.R. (2005). My Class Inventory - Short Form as an accountability tool for elementary school counsellors to measure classroom climate. Professional School Counseling, 9, 37-48.

Taylor, P.C., Fraser, B.J., \& Fisher, D.L. (1997). Monitoring constructivist classroom learning environments. International Journal of Educational Research, 27, 293-302.

Teh, G., \& Fraser, B.J. (1994). An evaluation of computer-assisted learning in terms of achievement, attitudes and classroom environment. Evaluation and Research in Education, 8, 147-161.

Teh, G., \& Fraser, B.J. (1995). Associations between student outcomes and geography classroom environments. International Research in Geographical and Environmental Education, 4(1), 318.

Walberg, H. J., \& Anderson, G. J. (1968). Classroom climate and individual learning. Journal of Educational Psychology, 59, 414-419.

Wolf, S.J., \& Fraser, B.J. (2008). Learning environment, attitudes and achievement among middleschool science students using inquiry-based laboratory activities. Research in Science Education, 38, 321-341.

Wong, A.F.L., \& Fraser, B.J. (1996). Environment-attitude associations in the chemistry laboratory classroom. Research in Science and Technological Education, 14, 91-102.

Wong, A.F.L., Young, D.J., \& Fraser, B.J. (1997). A multilevel analysis of learning environments and student attitudes. Educational Psychology, 17, 449-468.

Zandvliet, D., \& Fraser, B. J. (2004). Learning environments in information and communication technology classrooms. Technology, Pedagogy and Education, 13(1), 97-123.

Zandvliet, D.B., \& Fraser, B.J. (2005). Physical and psychosocial environments associated with networked classrooms. Learning Environments Research, 8, 1-17. 
Table 1 Summary of learning environment studies in Singapore

\begin{tabular}{|c|c|c|c|}
\hline Reference(s) & Subject \& grade & Sample(s) & Instrument \\
\hline $\begin{array}{l}\text { Teh and Fraser (1994, } \\
\text { 1995) }\end{array}$ & $\begin{array}{l}\text { Geography, } \\
\text { Secondary }\end{array}$ & $\begin{array}{l}\text { Geography class, } 671 \\
\text { high school students in } \\
24 \text { classes }\end{array}$ & $\begin{array}{l}\text { Geography Classroom } \\
\text { Environment Inventory }\end{array}$ \\
\hline $\begin{array}{l}\text { Wong and Fraser } \\
\text { (1996); Wong, Young } \\
\text { and Fraser (1997) }\end{array}$ & Chemistry, Grade 10 & 1592 Chemistry students & $\begin{array}{l}\text { Science Laboratory } \\
\text { Environment Inventory } \\
\text { (SLEI) }\end{array}$ \\
\hline $\begin{array}{l}\text { Quek, Wong and Fraser } \\
(2005)\end{array}$ & $\begin{array}{l}\text { Chemistry, } \\
\text { Secondary }\end{array}$ & $\begin{array}{l}497 \text { gifted and non- } \\
\text { gifted students }\end{array}$ & $\begin{array}{l}\text { Chemistry Laboratory } \\
\text { Environment Inventory } \\
\text { (CLEI); Questionnaire on } \\
\text { Teacher Interaction (QTI) }\end{array}$ \\
\hline $\begin{array}{l}\text { Goh and Fraser (1998, } \\
\text { 2000); Goh, Young and } \\
\text { Fraser (1995) }\end{array}$ & $\begin{array}{l}\text { Mathematics, } \\
\text { Primary } 5\end{array}$ & 1512 students & $\begin{array}{l}\text { Questionnaire on Teacher } \\
\text { Interaction (QTI primary); } \\
\text { My Class Inventory (MCI } \\
\text { primary) }\end{array}$ \\
\hline Pang (1999) & $\begin{array}{l}\text { Underachievers, } \\
\text { Primary } 4\end{array}$ & $\begin{array}{l}\text { Underachievers, primary } \\
4 \text { classroom }\end{array}$ & Case study \\
\hline Khoo and Fraser (2008) & $\begin{array}{l}\text { Computer education } \\
\text { centres }\end{array}$ & 250 adults & $\begin{array}{l}\text { What Is Happening in This } \\
\text { Class? (WIHIC) }\end{array}$ \\
\hline $\begin{array}{l}\text { Chionh and Fraser } \\
\text { (2009) }\end{array}$ & $\begin{array}{l}\text { Geography and } \\
\text { mathematics, Grade } \\
10\end{array}$ & 2310 students & $\begin{array}{l}\text { What is Happening In this } \\
\text { Class? (WIHIC) }\end{array}$ \\
\hline $\begin{array}{l}\text { Chua, Wong and Chen } \\
\text { (2011) }\end{array}$ & Chinese, secondary & $\begin{array}{l}\text { Chinese language, } 1460 \\
\text { secondary three students }\end{array}$ & $\begin{array}{l}\text { Chinese Language } \\
\text { Classroom Environment } \\
\text { Inventory (CLCEI) }\end{array}$ \\
\hline
\end{tabular}


Table 2 Factor analysis results for learning environment and attitude questionnaire

\begin{tabular}{|c|c|c|c|c|c|c|c|c|c|c|}
\hline \multirow{2}{*}{$\begin{array}{l}\text { Item } \\
\text { No }\end{array}$} & \multicolumn{10}{|c|}{ Factor Loadings } \\
\hline & IN & TS & IV & TO & $\mathrm{CO}$ & PR & UN & SN & SI & EJ \\
\hline 1 & 0.62 & & & & & & & & & \\
\hline 2 & 0.76 & & & & & & & & & \\
\hline 4 & 0.48 & & & & & & & & & \\
\hline 5 & 0.49 & & & & & & & & & \\
\hline 9 & & 0.66 & & & & & & & & \\
\hline 10 & & 0.74 & & & & & & & & \\
\hline 11 & & 0.73 & & & & & & & & \\
\hline 12 & & 0.67 & & & & & & & & \\
\hline 13 & & 0.64 & & & & & & & & \\
\hline 14 & & 0.69 & & & & & & & & \\
\hline 15 & & 0.56 & & & & & & & & \\
\hline 16 & & 0.46 & & & & & & & & \\
\hline 17 & & & 0.58 & & & & & & & \\
\hline 19 & & & 0.65 & & & & & & & \\
\hline 20 & & & 0.43 & & & & & & & \\
\hline 21 & & & 0.69 & & & & & & & \\
\hline 22 & & & 0.70 & & & & & & & \\
\hline 23 & & & 0.71 & & & & & & & \\
\hline 24 & & & 0.57 & & & & & & & \\
\hline 25 & & & & 0.51 & & & & & & \\
\hline 26 & & & & 0.50 & & & & & & \\
\hline 27 & & & & 0.45 & & & & & & \\
\hline 28 & & & & 0.58 & & & & & & \\
\hline 29 & & & & 0.62 & & & & & & \\
\hline 30 & & & & 0.58 & & & & & & \\
\hline 31 & & & & 0.65 & & & & & & \\
\hline 32 & & & & 0.52 & & & & & & \\
\hline 33 & & & & & 0.64 & & & & & \\
\hline 34 & & & & & 0.52 & & & & & \\
\hline 35 & & & & & 0.66 & & & & & \\
\hline 36 & & & & & 0.64 & & & & & \\
\hline 37 & & & & & 0.61 & & & & & \\
\hline 38 & & & & & 0.75 & & & & & \\
\hline 39 & & & & & 0.69 & & & & & \\
\hline 40 & & & & & 0.58 & & & & & \\
\hline 41 & & & & & & 0.52 & & & & \\
\hline 42 & & & & & & 0.48 & & & & \\
\hline 43 & & & & & & 0.50 & & & & \\
\hline 44 & & & & & & 0.72 & & & & \\
\hline 45 & & & & & & 0.61 & & & & \\
\hline 48 & & & & & & & 0.60 & & & \\
\hline 49 & & & & & & & 0.67 & & & \\
\hline 50 & & & & & & & 0.61 & & & \\
\hline 51 & & & & & & & 0.60 & & & \\
\hline 52 & & & & & & & 0.54 & & & \\
\hline 55 & & & & & & & & 0.61 & & \\
\hline 56 & & & & & & & & 0.64 & & \\
\hline 57 & & & & & & & & 0.68 & & \\
\hline 58 & & & & & & & & 0.64 & & \\
\hline 59 & & & & & & & & & 0.70 & \\
\hline 60 & & & & & & & & & 0.78 & \\
\hline 61 & & & & & & & & & 0.79 & \\
\hline 62 & & & & & & & & & 0.82 & \\
\hline 63 & & & & & & & & & 0.76 & \\
\hline 64 & & & & & & & & & 0.75 & \\
\hline 65 & & & & & & & & & & 0.70 \\
\hline 66 & & & & & & & & & & 0.78 \\
\hline 67 & & & & & & & & & & 0.75 \\
\hline 68 & & & & & & & & & & 0.81 \\
\hline 69 & & & & & & & & & & 0.84 \\
\hline 70 & & & & & & & & & & 0.78 \\
\hline$\%$ Variance & 27.92 & 5.48 & 5.22 & 4.62 & 3.47 & 3.24 & 2.68 & 2.27 & 2.05 & 1.95 \\
\hline Eigenvalue & 19.54 & 3.84 & 3.65 & 3.23 & 2.43 & 2.27 & 1.87 & 1.59 & 1.43 & 1.36 \\
\hline
\end{tabular}


$N=1081$ students in 55 classes.

Principal axis factoring with varimax rotation and Kaiser normalisation.

Factor loadings less than 0.40 have been omitted from the table.

Items 3, 6, 7, 8 and 18 were removed from the WIHIC scales and Items 46, 47, 53, and 54 were removed from the CLES scales. 
Table 3 Average item mean, average item standard deviation, internal consistency reliability (Cronbach alpha coefficient) and ability to differentiate between classrooms (ANOVA results) for learning environment and attitude scales

\begin{tabular}{|c|c|c|c|c|c|c|}
\hline Scale & $\begin{array}{l}\text { No of } \\
\text { items }\end{array}$ & $\begin{array}{c}\text { Unit of } \\
\text { analysis }\end{array}$ & $\begin{array}{c}\text { Average } \\
\text { item mean }\end{array}$ & $\begin{array}{l}\text { Average } \\
\text { item SD }\end{array}$ & $\begin{array}{c}\text { Alpha } \\
\text { reliability }\end{array}$ & $\begin{array}{c}\text { ANOVA } \\
E^{2 t a}{ }^{2}\end{array}$ \\
\hline \multicolumn{7}{|l|}{ Learning Environment } \\
\hline \multirow[t]{2}{*}{ Involvement } & 4 & Individual & 3.22 & 0.79 & 0.79 & $0.12 *$ \\
\hline & & Class Mean & 3.24 & 0.27 & 0.87 & \\
\hline \multirow[t]{2}{*}{ Teacher Support } & 8 & Individual & 3.37 & 0.86 & 0.89 & $0.13 *$ \\
\hline & & Class Mean & 3.39 & 0.33 & 0.94 & \\
\hline \multirow[t]{2}{*}{ Investigation } & 7 & Individual & 3.05 & 0.86 & 0.88 & $0.09 *$ \\
\hline & & Class Mean & 3.06 & 0.26 & 0.91 & \\
\hline \multirow[t]{2}{*}{ Task Orientation } & 8 & Individual & 4.05 & 0.68 & 0.86 & $0.13 *$ \\
\hline & & Class Mean & 4.05 & 0.24 & 0.91 & \\
\hline \multirow[t]{2}{*}{ Cooperation } & 8 & Individual & 3.83 & 0.75 & 0.90 & $0.11 *$ \\
\hline & & Class Mean & 3.85 & 0.25 & 0.93 & \\
\hline \multirow[t]{2}{*}{ Personal Relevance } & 5 & Individual & 3.81 & 0.80 & 0.84 & $0.08 *$ \\
\hline & & Class Mean & 3.84 & 0.23 & 0.89 & \\
\hline \multirow[t]{2}{*}{ Uncertainty } & 5 & Individual & 3.71 & 0.82 & 0.77 & $0.06 * *$ \\
\hline & & Class Mean & 3.72 & 0.21 & 0.77 & \\
\hline \multirow[t]{2}{*}{ Student Negotiation } & 4 & Individual & 3.26 & 0.91 & 0.86 & $0.09 *$ \\
\hline & & Class Mean & 3.28 & 0.29 & 0.91 & \\
\hline \multicolumn{7}{|l|}{ Attitudes } \\
\hline \multirow[t]{2}{*}{ Inquiry } & 6 & Individual & 3.74 & 1.02 & 0.91 & \\
\hline & & Class Mean & 3.72 & 0.28 & 0.93 & \\
\hline \multirow{2}{*}{ Enjoyment } & 6 & Individual & 3.62 & 1.08 & 0.94 & \\
\hline & & Class Mean & 3.63 & 0.49 & 0.98 & \\
\hline
\end{tabular}


Table 4 Three-way ANOVA Results $\left(F\right.$ and $\left.\mathrm{Eta}^{2}\right)$ for Gender, Grade-level and Stream Differences for Learning Environment and Attitude Scales

\begin{tabular}{|c|c|c|c|c|c|c|c|c|c|c|c|c|c|c|}
\hline \multirow{3}{*}{ Scale } & \multicolumn{12}{|c|}{ Three-way ANOVA results } & & \\
\hline & \multicolumn{2}{|c|}{ Sex } & \multicolumn{2}{|c|}{ Grade } & \multicolumn{2}{|c|}{ Stream } & \multicolumn{2}{|c|}{ StreamxSex } & \multicolumn{2}{|c|}{ GradexStream } & \multicolumn{2}{|c|}{ GradexSex } & \multicolumn{2}{|c|}{ StreamxSexxGrade } \\
\hline & $F$ & $\mathrm{Eta}^{2}$ & $F$ & $\mathrm{Eta}^{2}$ & $F$ & $\mathrm{Eta}^{2}$ & $F$ & Eta $^{2}$ & $F$ & Eta $^{2}$ & $F$ & $\mathrm{Eta}^{2}$ & $F$ & $\mathrm{Eta}^{2}$ \\
\hline \multicolumn{15}{|l|}{ Learning Environment } \\
\hline Involvement & $17.39^{* *}$ & 0.02 & 0.69 & 0.00 & $3.05^{*}$ & 0.00 & 1.78 & 0.00 & 1.76 & 0.00 & 0.83 & 0.00 & 2.45 & 0.00 \\
\hline Teacher Support & $4.36^{*}$ & 0.00 & $9.06^{* * *}$ & 0.01 & 0.01 & 0.00 & 2.04 & 0.00 & 1.52 & 0.00 & 1.81 & 0.00 & 1.45 & 0.00 \\
\hline Investigation & 2.36 & 0.00 & 0.08 & 0.00 & 0.25 & 0.00 & 0.03 & 0.00 & $3.80^{*}$ & 0.00 & 2.26 & 0.00 & 0.75 & 0.00 \\
\hline Task Orientation & $12.26^{* *}$ & 0.01 & $9.57^{* *}$ & 0.02 & 0.93 & 0.00 & $3.56^{*}$ & 0.00 & 2.85 & 0.00 & 0.07 & 0.00 & 2.40 & 0.00 \\
\hline Cooperation & $15.29^{* *}$ & 0.01 & $3.59 *$ & 0.00 & $2.95^{*}$ & 0.00 & 0.18 & 0.00 & 0.49 & 0.00 & 0.85 & 0.00 & 0.01 & 0.00 \\
\hline Personal Relevance & 1.31 & 0.00 & 2.47 & 0.00 & $7.17^{* *}$ & 0.01 & 2.65 & 0.00 & 0.20 & 0.00 & 0.31 & 0.00 & 2.07 & 0.00 \\
\hline Uncertainty & 0.16 & 0.00 & 0.48 & 0.00 & 0.10 & 0.00 & 2.79 & 0.00 & 1.73 & 0.00 & 1.12 & 0.00 & 2.39 & 0.00 \\
\hline Student Negotiation & 0.03 & 0.00 & 2.82 & 0.00 & 1.75 & 0.00 & 0.35 & 0.00 & $4.75^{* *}$ & 0.01 & 1.02 & 0.00 & 2.38 & 0.00 \\
\hline \multicolumn{15}{|l|}{ Attitudes } \\
\hline Inquiry & 1.49 & 0.00 & 1.48 & 0.00 & 0.07 & 0.00 & 1.91 & 0.00 & $4.09^{* *}$ & 0.00 & 0.46 & 0.00 & 0.00 & 0.00 \\
\hline Enjoyment & 1.24 & 0.00 & $7.26^{* *}$ & 0.01 & 1.02 & 0.00 & $6.15^{*}$ & 0.00 & $4.69^{* *}$ & 0.01 & 2.40 & 0.00 & 2.23 & 0.00 \\
\hline
\end{tabular}

$* p<0.05, * * p<0.01$

Sample size $=1081$ students in 55 classes

$\mathrm{Eta}^{2}$ represents the proportion of variance in a dependent variable explained by an independent variable. 
Table 5 Average item mean, average item standard deviation and difference between sex (ANOVA result and effect size) for each learning environment and attitude scale

\begin{tabular}{|c|c|c|c|c|c|c|}
\hline \multirow[t]{2}{*}{ Scale } & \multicolumn{2}{|c|}{ Average item mean } & \multicolumn{2}{|c|}{ Average item SD } & \multicolumn{2}{|c|}{ Difference } \\
\hline & Male & Female & Male & Female & $F$ & $\begin{array}{l}\text { Effect } \\
\text { size }\end{array}$ \\
\hline \multicolumn{7}{|l|}{ Learning Environment } \\
\hline Involvement & 3.31 & 3.08 & 0.78 & 0.80 & $17.39^{* *}$ & 0.29 \\
\hline Teacher Support & 3.32 & 3.44 & 0.86 & 0.85 & $4.36^{*}$ & -0.14 \\
\hline Investigation & 3.08 & 3.01 & 0.86 & 0.87 & 2.36 & 0.08 \\
\hline Task Orientation & 3.98 & 4.14 & 0.70 & 0.65 & $12.26^{* *}$ & -0.23 \\
\hline Cooperation & 3.75 & 3.96 & 0.77 & 0.71 & $15.29^{* *}$ & -0.28 \\
\hline Personal Relevance & 3.82 & 3.80 & 0.81 & 0.79 & 1.31 & 0.02 \\
\hline Uncertainty & 3.72 & 3.71 & 0.82 & 0.82 & 0.16 & 0.01 \\
\hline Student Negotiation & 3.26 & 3.25 & 0.93 & 0.88 & 0.03 & 0.01 \\
\hline \multicolumn{7}{|l|}{ Attitudes } \\
\hline Inquiry & 3.70 & 3.79 & 1.05 & 0.97 & 1.49 & -0.08 \\
\hline Enjoyment & 3.64 & 3.58 & 1.11 & 1.03 & 1.24 & 0.05 \\
\hline
\end{tabular}

$*_{p}<0.05,{ }^{*} p<<0.01$

Sample size $=665$ (males) and 416 (females) 
Table 6 Average item mean, average item standard deviation and difference between grade levels (ANOVA result and effect size) for each learning environment and attitude scale

\begin{tabular}{|c|c|c|c|c|c|c|c|c|}
\hline \multirow[t]{3}{*}{ Scale } & \multirow{2}{*}{\multicolumn{3}{|c|}{$\begin{array}{c}\begin{array}{c}\text { Average item } \\
\text { mean }\end{array} \\
\text { Grade }\end{array}$}} & \multirow{2}{*}{\multicolumn{3}{|c|}{$\begin{array}{c}\text { Average item SD } \\
\text { Grade }\end{array}$}} & \multicolumn{2}{|c|}{ Difference } \\
\hline & & & & & & & \multirow[t]{2}{*}{$F$} & \multirow[t]{2}{*}{$\mathrm{Eta}^{2}$} \\
\hline & 4 & 5 & 6 & 4 & 5 & 6 & & \\
\hline \multicolumn{9}{|l|}{ Learning Environment } \\
\hline Involvement & 3.21 & 3.21 & 3.26 & 0.82 & 0.80 & 0.76 & 0.69 & 0.00 \\
\hline Teacher Support & 3.36 & 3.26 & 3.54 & 0.87 & 0.86 & 0.81 & $9.06^{* *}$ & 0.01 \\
\hline Investigation & 3.03 & 3.07 & 3.04 & 0.85 & 0.87 & 0.88 & 0.08 & 0.00 \\
\hline Task Orientation & 4.09 & 3.93 & 4.12 & 0.69 & 0.72 & 0.62 & $9.57^{* *}$ & 0.01 \\
\hline Cooperation & 3.80 & 3.80 & 3.93 & 0.79 & 0.77 & 0.68 & $3.59^{*}$ & 0.01 \\
\hline Personal Relevance & 3.84 & 3.77 & 3.85 & 0.82 & 0.82 & 0.76 & 2.47 & 0.00 \\
\hline Uncertainty & 3.69 & 3.70 & 3.76 & 0.81 & 0.82 & 0.84 & 0.48 & 0.00 \\
\hline Student Negotiation & 3.28 & 3.19 & 3.32 & 0.95 & 0.95 & 0.79 & 2.82 & 0.00 \\
\hline \multicolumn{9}{|l|}{ Attitudes } \\
\hline Inquiry & 3.78 & 3.75 & 3.65 & 0.99 & 1.04 & 1.04 & 1.48 & 0.00 \\
\hline Enjoyment & 3.75 & 3.55 & 3.53 & 1.06 & 1.10 & 1.07 & $7.26^{* *}$ & 0.01 \\
\hline
\end{tabular}

Sample size $=394($ Grade 4$), 401$ (Grade 5) and 286 (Grade 6)

$* p<0.05, * * p<0.01$ 
Table 7 Average item mean, average item standard deviation and difference between streams (ANOVA result and effect size) for each learning environment and attitude scale

\begin{tabular}{|c|c|c|c|c|c|c|}
\hline \multirow[t]{2}{*}{ Scale } & \multicolumn{2}{|c|}{$\begin{array}{c}\text { Average item } \\
\text { mean }\end{array}$} & \multicolumn{2}{|c|}{ Average item SD } & \multicolumn{2}{|c|}{ Difference } \\
\hline & GE & HA & GE & HA & $F$ & Effect Size \\
\hline \multicolumn{7}{|l|}{ Learning Environment } \\
\hline Involvement & 3.28 & 3.16 & 0.78 & 0.81 & $3.05^{*}$ & 0.15 \\
\hline Teacher Support & 3.35 & 3.39 & 0.84 & 0.87 & 0.01 & -0.04 \\
\hline Investigation & 3.04 & 3.06 & 0.85 & 0.88 & 0.25 & -0.02 \\
\hline Task Orientation & 3.99 & 4.10 & 0.68 & 0.68 & 0.93 & -0.16 \\
\hline Cooperation & 3.78 & 3.90 & 0.74 & 0.77 & $2.95^{*}$ & -0.15 \\
\hline Personal Relevance & 3.75 & 3.89 & 0.82 & 0.78 & $7.17 * *$ & -0.17 \\
\hline Uncertainty & 3.70 & 3.73 & 0.82 & 0.82 & 0.10 & -0.03 \\
\hline Student Negotiation & 3.29 & 3.22 & 0.89 & 0.94 & 1.75 & 0.07 \\
\hline \multicolumn{7}{|l|}{ Attitudes } \\
\hline Inquiry & 3.70 & 3.78 & 1.05 & 1.00 & 0.07 & -0.07 \\
\hline Enjoyment & 3.56 & 3.69 & 1.10 & 1.06 & 1.02 & -0.12 \\
\hline
\end{tabular}

$* p<0.05, * * p<0.01$

Sample size $=569(\mathrm{GE})$ and $512(\mathrm{HA})$ 


\section{Figures}

Fig. 1 Sex-by-stream interactions for learning environment and attitude scales

Fig. 2 Grade-by-stream interactions for two learning environment scales and two attitude scales 


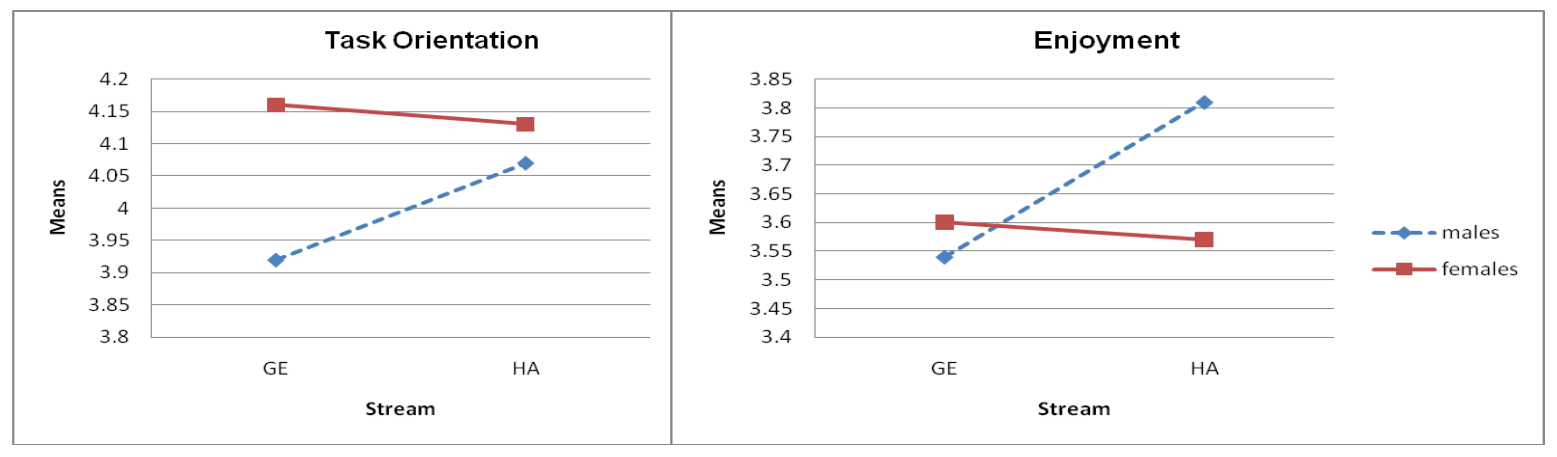

Fig. 1 


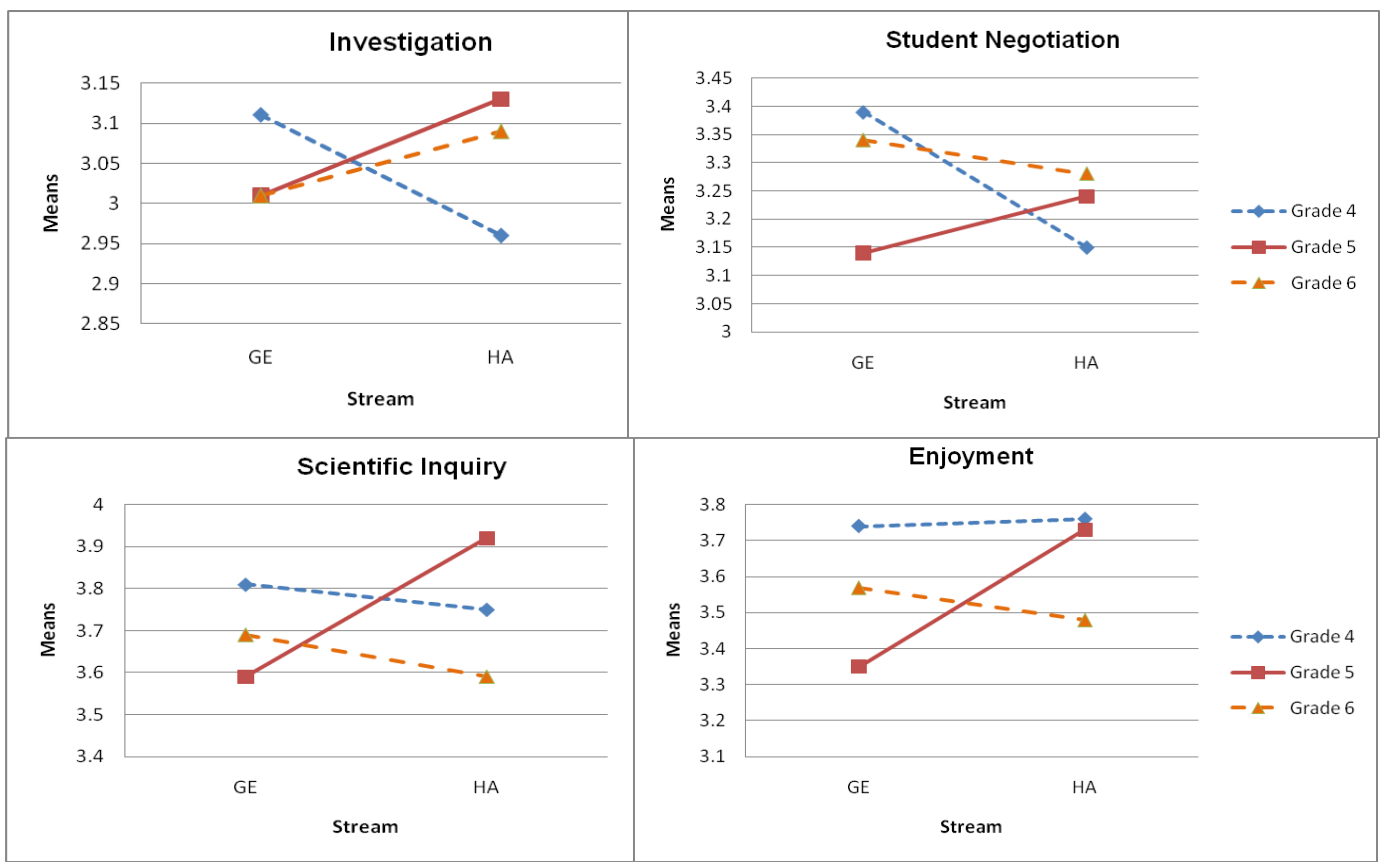

Fig. 2 